\title{
Analysis of the Consumption of Electric Consumers in China 'S Color TV--Taking the Sales of TV Electrical Manufacturers in 2015 as an Example
}

\author{
Feng $\mathrm{Li}^{1}$, Li Zhou ${ }^{2}$, Lei Chen ${ }^{2}$, Gengsi Lv ${ }^{3}$ \\ ${ }^{1}$ China Center for Industrial Security Research, Beijing Jiaotong University; School of information, \\ Beijing Wuzi University, Beijing, China \\ 2 School of information, Beijing Wuzi University, Beijing, China \\ ${ }^{3}$ Consulting Service Veritas Technologies (Beijing) Co., Ltd. Beijing, China
}

Keywords: Internet has, electricity consumption model, cities nationwide.

\begin{abstract}
With the development of high-tech, the popularization of the Internet has brought great opportunities andy, the development of home appliance industry has formed a relatively stable model and scale. But by the Internet technology and other high-tech impact, which had to seek business model changes and industrial development on the transformation. This paper analyzes the sales data of TV commercials in $31 \mathrm{pr}$ challenges to the development of e-commerce in the home appliance industry. In the traditional industr ovinces and cities nationwide, and finally puts forward the electricity business model of home appliance industry, and explores how to set up the general framework and specific strategy to provide reference for the electricity consumption model of China's household electrical appliance industry.
\end{abstract}

\section{Introduction}

In recent years, the rapid development of Internet TV, consumers watch the TV program awareness began to become increasingly popular in many traditional industries have encountered the impact from the Internet business, the traditional TV manufacturing industry is also aware that this is the trend of the times and the market environment Choice, the transition is imminent to Haier as the representative of many traditional home appliance enterprises have also introduced the electricity business model.

The reason why the electricity business model can quickly affect the market, with the Internet companies to use its unique marketing advantages, to seize people easy to produce new things in the curiosity inseparable. In the big environment of the trend, the home appliance industry to carry out technical transformation without delay. Based on the current home appliance industry, the development of online consumption is slightly slow, despite the existence of the advantages of fast and low prices, but by the physical store of the long-term development of the terminal business, based on the strong demand for product quality, therefore, for the line Under the consumption of another time to pick up, online consumption gradually sink the status quo, this paper based on large data related technology, collecting semi-structured web data, China's home appliance industry, electricity consumption analysis.

\section{Literature Review}

Since the 1980s, Western scholars have been engaged in the controversy over the conceptual assumptions about consumer behavior, and scholars have disagreed. Scholars, who are based on the basic theory of microeconomics, argue that consumer behavior is a measure of their own income before making a decision, while analyzing their own hobbies and Preferences, and finally choose to buy to meet their needs to maximize the combination of goods in order to achieve maximum utility. According to Blackwell et al., Consumer behavior is not a single activity but a series of activities that include the acquisition, consumption, and processing of the product or service by the consumer. 
According to Kotter's research, it is concluded that the behavior of consumers is the process of selection, purchase, use and processing of individuals, groups and organizations in order to meet their needs and desires. Sheth and Mittal argue that consumer behavior is the process of consumer activity in the individual and the psychological and real life of the consumer, which includes the purchase and use of the product or service by the consumer. Solomon defines consumer behavior as a process by which a consumer's individual or group is actually involved in satisfying his own needs and desires. This process includes the selection, purchase, use, and disposition of a product, vision, experience, or service.

The concept of consumer behavior is defined on the background of different theoretical perspectives. "Decision-making process theory" considers that the behavior of consumers is a decision-making process. The process of decision-making includes the purchase of products or services, Use and processing. In the process of consumer decision-making, the realization of the actual behavior of consumers will be affected by both internal and external factors. But the flaw in this theory is that only the behavior of consumers is a purchase decision-making behavior. "Experience" is that the behavior of consumers in the process of emotional factors are more than the rational factors, the theory that should pay attention to the actual experience of consumers, consumers are in the process of experience with the purchase, consumption and disposal behavior of. The theory is based on the consumer demand point of view to analyze the behavior of consumers, indicating the purpose of their behavior, "stimulus - response theory" that consumer behavior is to stimulate the external factors to respond, consumption Behavioral research should be based on the relationship between consumer and stimulating factors. "Balanced coordination theory" that consumer behavior is the consumer and business marketers betray each other, take the required behavior process, the result is the need to achieve the balance between the interests of each other.

Based on the realization of the model of consumer exchange, that customers and enterprises in the process of actual activities will be affected by the surrounding environmental factors (the group, family, culture and the situation, etc.) impact. For consumers, it will be faced with its own environmental factors to absorb the digestion and analysis, after these environmental factors will have a consumer exchange behavior with the corresponding impact. For the marketers, the need for changes in external environmental factors to make rapid and appropriate adjustments to the environment in which enterprises are analyzed, the conduct of consumer conduct in-depth investigation and study, and ultimately the formation of enterprises and consumers conducive to a win-win situation The related strategies and measures of exchange behavior. At the same time, the exchange of behavior between enterprises and consumers also need to build on the basis of a certain interaction and interaction. As the purpose of the behavior of consumers and habits are different, during the various stimuli by the digestion results, the reaction is not the same, so the behavior is also different. Nevertheless, these seemingly different acts, there are still regular things. At present, scholars at home and abroad respectively put forward different theoretical models to test the behavior of consumers on different behaviors of consumers' behavior. This article from the annual sales of the monthly point of view of the brand classification. This article as far as possible will be divided into a class of home appliances sales.

\section{Empirical Research}

\subsection{Brand Selection Basis}

The first three quarters of 2015, Hisense TV global sales share of 5.8\%, surpassing Sony, ranking the world's top three. From the second quarter, Hisense TV rapid development, to November reached a maximum value of 22.4487 billion yuan, an increase of 1.65 . And Hisense TV is similar to the growth of Samsung, although its share is smaller than the other, but still the same year the growth rate of 1.69 development. Konka development is also quite rapid, to November reached a maximum value of 12.7788 billion yuan, an increase of 1.83. The fastest growth rate is the LeTV TV, in November 2015 reached a maximum value of 14.4403 billion yuan, an increase of 2.59. Haier's development is more average, but fell by 0.29 year on year. Haier is the leading enterprises in the domestic appliance 
industry, its development on the micro-inevitable in the development process encountered both internal and external factors, it is necessary for the development of other enterprises in the process of understanding and analysis of Haier. Based on this, this article selected the above five TV brands, as the object of study.

\subsection{Data Acquisition Technology}

Data acquisition technology is the use of C \# WinForm form developed on a set of distributed data acquisition system. In the electricity platform to collect TV-related data, some sites are anti-crawler ability. After repeated browsing web data, it is likely that the site will close your IP address, so you can not go to browse the site of the page, and also get the data you want, so in order to prevent the site IP, Accurate collection of relevant data, then use a rental remote server, that is, VPS. The design of a distributed collection system remote deployment to multiple VPS, the use of VPS to collect the data we want. If there is a phenomenon of IP closure, before the development of a good collection system will automatically replace the IP, continue to collect. The acquisition system not only automatically replaces the IP, but also disconnects the network. In the VPS collection, it is likely that a remote service network connection error, interrupted, can not browse the web, then the acquisition system will automatically connect. Collected data is very much, every day will be automatically saved to our database, save the database, in order to ensure that the monthly sales of more accurate TV, so the information will be collected every week to remove duplicate information. The data collected on the day is the previous day's sales data, the acquisition program will not run until the acquisition is complete. At this time also need to deploy a time on the VPS monitoring, it is equivalent to a timer, time monitoring time, the acquisition program will automatically start.

\subsection{Data Sources}

At present, my country has a lot of electricity business platform. However, from the sales and brand effect, the most important is the day cat, Taobao, Jingdong, Gome, Suning, Amazon, Dangdang, one shop eight. This article is based on the above large data collection technology, based on the monthly collection of the above eight business platform in 2015 the country's 31 provinces and cities about 5 different brands of TV commercial sales data (Table 1).

Table 1 five brands of TV commercial sales data in 31 provinces and cities in 2015

\begin{tabular}{|c|c|c|c|c|c|c|}
\hline & January & February & March & April & May & June \\
\hline Haier & 23260 & 24142 & 13974 & 20746 & 26581 & 29955 \\
\hline Hisense & 32012 & 31372 & 47975 & 74317 & 82374 & 114439 \\
\hline Konka & 16963 & 13689 & 21537 & 68155 & 66278 & 79343 \\
\hline LeTV & 16988 & 19001 & 34977 & 57368 & 57754 & 79701 \\
\hline Samsung & 7584 & 5361 & 22362 & 86427 & 68586 & 57261 \\
\hline & July & August & September & October & November & December \\
\hline Haier & 20083 & 24062 & 23561 & 23132 & 36906 & 16345 \\
\hline Hisense & 64727 & 102412 & 88365 & 98544 & 224487 & 85014 \\
\hline Konka & 47230 & 75300 & 61541 & 61927 & 127788 & 48049 \\
\hline LeTV & 40978 & 75052 & 62791 & 53499 & 144403 & 61155 \\
\hline Samsung & 40900 & 73255 & 51222 & 48609 & 101985 & 20409 \\
\hline
\end{tabular}

\subsection{Data Processing Tools}

The data processing tool used in this paper is SAS, full name STATISTICAL ANALYSIS SYSTEM, by the United States North CAROLINA State University 1966 developed statistical analysis software. SAS is a large-scale integrated information system for decision support, but the earliest functions of the software system are limited to statistical analysis. So far, statistical analysis is still an important component and core function.

SAS system mainly to complete the data-centric four tasks: data access; data management (sas data management function is not very good, but the data analysis is strong, so often use Microsoft's product management data, and then lead into sas data format . Please pay attention to supporting the use of other software); data presentation; data analysis. The Base SAS module is the core of the SAS system, responsible for data management, interactive application environment management, user language processing, call other SAS modules. Base SAS provides a wealth of data management capabilities for the SAS system's database and also supports standard SQL language for data 
manipulation. Base SAS can produce from simple list to more complex statistical reports. Base SAS can be the basic descriptive statistics and the basis of correlation coefficient calculation, the normal distribution test.

\subsection{Research Methods}

This article needs to study is that the brand effect of home appliances on household appliances sales data whether there is a significant role. Based on this, this paper adopts the method of single factor analysis of variance.

One-way ANOVA is used to compare the number of samples with a completely random design. The statistical inference is to infer whether the population mean is equal to each other.

Completely random design does not take into account the effects of individual differences, involving only one processing factor, but can have two or more levels, so also known as single factor experimental design. In the experimental study, the subjects were randomly assigned to a plurality of levels of treatment factors according to the principle of randomization, and then the experimental effects of each group were observed. In the observation study (survey), the subjects were grouped according to the different levels of the research factors, Compare the effect of this factor.

In the one-way analysis of variance, in order to describe and calculate the use of convenience, usually with the capital letters $A$ factor factor $m$ different values represent $m$ different levels, respectively, with $A 1, A 2, \ldots, A m$ to represent, in each $(N=1,2, \ldots n ; j=1,2, \ldots, m)$ is taken as the ith sample taken from the jth. It can be considered that it is factor A The difference between the jth level of $\alpha_{j}=\mu_{+} \varepsilon_{j}, \varepsilon_{j}$ can be considered that it is factor A The difference between the jth level of $\mathrm{Aj}$. Therefore, there is a significant difference between the levels of the test factor $A$, which is equivalent to the test: H0: ${ }^{\alpha} 1={ }^{\alpha} 2=\ldots={ }^{\alpha} m=\mu$ or H0: ${ }^{\varepsilon_{1}}={ }^{\varepsilon_{2}}=\ldots={ }^{\varepsilon} \mathrm{m}=0$, single factor specific analysis test procedure is below:

(1) Calculate the mean value

Let $\bar{x}$ jdenote the mean value of the sample at the jth level, and $x \mathrm{j}$ is calculated as

$$
x_{j}=\frac{\sum_{i-1}^{n_{j}} x_{i j}}{n_{j}}
$$

(2) Calculate the sum of the squared deviations

In the one-way ANOVA, there are three squares of the variance, which are the sum of the squared sums of the total deviations, the squared sum of the group deviations and the sum of squares. The square sum of the total deviation is represented by SST. The formula is shown in (2). The square sum of the group deviations is denoted by SSE. The formula is shown in (3). The square sum of the groups is expressed by SSA. ).

$$
\begin{gathered}
S S T=\sum \sum\left(X_{i j}-\bar{X}\right)^{2} \\
S S E=\sum_{j}\left[\sum_{i}\left(X_{i j}-\overline{X_{j}}\right)^{2}\right] \\
S S A=\sum \sum\left(X_{j}-\bar{X}\right)^{2}=\sum n_{j}\left(X_{j}-\bar{X}\right)^{2}
\end{gathered}
$$

The squares of the deviations of the mean values are subtracted by the mean of the groups, multiplied by the number of observations in each group, and then summed to obtain SSA. It can be seen that it shows the difference between groups. Which includes both random and systemic factors. According to the proof, there is a certain connection between the three, this link in the performance: SST $=$ SSE + SSA.

(3) Calculate the mean square

For SSA, the mean square MSA is: MSA = square sum / degrees of freedom = SSA / (m- 1$)$; for SSE, the mean square MSE is: MSE = square sum / The

(4) variance analysis table:

$\mathrm{F}=$ Intergroup variance $/$ group variance $=$ MSA $/$ MSE 
In order to make the main process of variance analysis more clearly, the calculation results are usually classified as variance analysis table (see Table 2).

Table 2 Analysis of variance

\begin{tabular}{|c|c|c|c|c|}
\hline Variance source & $\begin{array}{c}\text { variance square sum } \\
(\mathrm{SS})\end{array}$ & $\begin{array}{c}\text { degree of freedom } \\
(\mathrm{df})\end{array}$ & $\begin{array}{c}\text { mean square } \\
(\mathrm{MS})\end{array}$ & F value \\
\hline Between groups & SSA & $\mathrm{m}-1$ & MSA & \\
In Group & SSE & $\mathrm{n}-\mathrm{m}$ & MSA & \\
Total difference & SST & $\mathrm{n}-1$ & \\
\hline
\end{tabular}

(5) make judgments

For a given level of significance ${ }^{\alpha}$, the $F$ value is found by the $F$ distribution table $F^{\alpha}$. If $F>F^{\alpha}$, the original hypothesis is rejected, indicating that the factor has a significant effect on the index. If $\mathrm{F}<=$ $\mathrm{F}^{\alpha}$, then the original hypothesis The effect of different levels on the experimental results was not significant.

\subsection{Research Steps}

First of all, this article on the different home appliance business platform for monthly sales data to carry out the basic analysis, analysis of the results see (Figure 2), 1 on behalf of the Haier brand, 2 on behalf of Hisense brand, 3 on behalf of Konka brand, 4 on behalf of LeTV brand, 5 on behalf of Samsung brand The Can be seen from the figure, the current home appliance brand sales data does not exist left or right deviation. But the brand Hisense, Konka, LeTV as there is a singular point; brand Haier and Samsung no singularity, but this does not affect the follow-up data processing results, therefore, can ignore this phenomenon. At the same time, the brand Haier's monthly sales data difference is small.

Secondly, this paper analyzes the single factor analysis of variance of monthly sales data of home appliance business platform. Univariate analysis of variance refers to the method of single factor test results, test factors on the test results have no significant impact on the method. One-way ANOVA is the sum of the squared differences between the groups and the group. Two or more groups of data, large group all in a group is the group, to calculate the average of each group, and then from the square sum of the calculation. The purpose of the one-way ANOVA is to randomly assign the subjects to multiple levels of a treatment factor according to the principle of randomization in the experimental study, and then observe the experimental effects of each group. In the observation study (survey) Different factors of the study group, compare the effect of this factor.

\section{Data Processing Results}

From the analysis of the results, 1,3,4,5 in the one-way analysis of variance, can be considered no difference, and therefore can be classified as a class; 2,3,4,5 can also be classified as the same category.

Therefore, it can be considered that, based on the paper sales data of home appliance manufacturers, we can see: Haier, Konka, LeTV, Samsung in the eight major business platform sales in 2015 there is no significant difference; Hisense, Konka, LeTV, There are no significant differences.

\section{Conclusion}

Electricity industry environment, home appliance industry, the transformation of the consumption model is imperative, its feasibility is mainly reflected in the first policy to promote the appliance industry to promote the transformation and transformation of consumption patterns, the second network consumer market continues to expand the provision of conditions for the transformation of the consumption model, the third The development of mobile Internet data to provide technical support for the transformation of consumption patterns, the fourth supply chain for the transformation 
of the supply model to provide supply support four aspects. And its own transformation of the inevitable.

Although with the growing popularity of the Internet, China's home appliance industry development model is still mainly dependent on the development of the store, but simply relying on the traditional store marketing model to sell the formation of the consumption model, although there is still a huge irreplaceable, but only Rely on the store is easy because of the Internet out of line with the market was eliminated, therefore, the Internet technology to the actual development of the appliance industry is essential.

Finally, the appliance industry, electricity consumption model specific strategies put forward two proposals, the first is for the enterprise structure of the adjustment, the second is the level of service on the increase. Home appliance industry, consumption patterns change is imperative. The realization of $\mathrm{O} 2 \mathrm{O}$ consumption model changes, mainly reflected in the existence of relying on the existence of the store, through the development of online business, and line with the business of convergence, both through the simultaneous development of the joint development of resources, products and consumption and other Aspects of the advantages, and ultimately to enlarge the main features to promote the development of the industry.

\section{Acknowledgements}

This paper is funded by the project of National Natural Science Fund, Research on the warehouse picking system blocking influence factors and combined control strategy (Project number: 71501015); and funded by intelligent logistics system Collaborative Innovation Center and Beijing Key Laboratory (No.BZ0211); and funded by 0351701301Science and technology innovation service capacity building-Construction of scientific research base-Collaborative innovation center of intelligent logistics system (Project number:PXM2017_014214_000013); 2017Personnel training quality construction -Specialty construction-Professional group construction in Beijing(PXM2017_014214_000010).

\section{References}

[1]. RanjayGulati and Jason Garino Getthe Right Mix of Bricks and Clicks[J].Harvard Business Review, May-June 2000: 107-114. (references)

[2]. J. Clerk Maxwell, A Treatise on Electricity and Magnetism, 3rd ed., vol. 2. Oxford: Clarend Tung-Ju Wu,Ren-Hui Zhao,Shian-Yang Tzeng. An empirical research of consumer adoption behavior on catering transformation to mobile $\mathrm{O} 2 \mathrm{O}[\mathrm{J}]$. Journal of Interdisciplinary Mathematics,2015,186.on, 1892, pp.68-73.

[3]. Yao Guozhang.From Wal-Mart to see the traditional retailer's e-commerce development and transformation [J].Journal of Nanjing University of Posts and Telecommunications (Social Science Edition), 2011,01: 27-33.

[4]. Cai Hongling.Research on Logistics Distribution Model Selection of Home Appliance Chain Based on O2O "Double Line" Integration [D].Nanchang University, 2015.

[5]. Li Guorong.Study on the Development Model of Logistics and Supply Chain in Home Appliance Chain Enterprises [D]. Southwest Jiaotong University, 2011.

[6]. Chu Yixiang.O2O model of the furniture industry operating model research [D]. Hefei University of Technology, 2013.

[7]. M. Young, The Technical Writer’s Handbook. Mill Valley, CA: University Science, 1989. 